\title{
The Atrial Fibrillation in Turkey: Epidemiologic Registry (AFTER)
}

\author{
Faruk Ertas ${ }^{1}$, Nihan Kahya Eren ${ }^{2}$, Hasan Kaya ${ }^{1}$, Alpay Aribas ${ }^{3}$, Goksel Acar ${ }^{4}$, \\ Mehmet Kanadasi ${ }^{5}$, Selcuk Gedik ${ }^{6}$, Mustafa Oylumlu ${ }^{1}$, Murat Yuksel ${ }^{1}$, \\ Mehmet S. Ulgen ${ }^{1}$; for the AFTER Investigators \\ ${ }^{1}$ Department of Cardiology, Dicle University Faculty of Medicine, Diyarbakir, Turkey \\ ${ }^{2}$ Department of Cardiology, Ataturk Education and Research Hospital, Izmir, Turkey \\ ${ }^{3}$ Department of Cardiology, Selcuk University Meram Faculty of Medicine, Konya, Turkey \\ ${ }^{4}$ Department of Cardiology, Kartal Kosuyolu Education and Research Hospital, Istanbul, Turkey \\ ${ }^{5}$ Department of Cardiology, Cukurova University Faculty of Medicine, Adana, Turkey \\ ${ }^{6}$ Cardiovascular Clinic, Ankara Numune Education and Research Hospital, Ankara, Turkey
}

\begin{abstract}
Background: AFTER (Atrial Fibrillation in Turkey: Epidemiologic Registry) is a prospective, multicenter study designed with the aim of describing the prevalence and epidemiology of AF practice in Turkey. This study aims to evaluate stroke risk in non-valvular atrial fibrillation $(A F)$ and anticoagulant drug utilization within conformity to AF guidelines.

Methods: Patients were recruited in 17 referral hospitals reflecting all the population of 7 geographical regions of Turkey. 2242 consecutive patients who had been admitted with AF on ECG were included in the study. 1745 of these patients, who had non-valvular AF, were included in the statistical evaluation. Stroke risk was evaluated with the $\mathrm{CHA}_{2} D \mathrm{~S}_{2}$-VASc score.

Results: The average age of participants was determined to be $69.2 \pm 11.5$ years $(56 \%$ female). Persistent-permanent $A F$ was found to be the most common type of non-valvular AF (78\%). The most common comorbid disorder was hypertension (73\%). It was found that oral anticoagulant therapy was used by $40 \%$ of all patients, $37 \%$ of whom had effective INR (2.0-3.0). Upon multivariate analysis, age was found to be the only independent predictor of stroke among the variables' effects on thromboembolic events that created $\mathrm{CHA}_{2} D \mathrm{~S}_{2}-V A S c$ abbreviations (OR 1.026, $p<0.001)$.

Conclusions: These results suggest that stroke risk scores should be thoroughly heeded based on guidelines, and that anticoagulation must be applied according to their guidance. (Cardiol J 2013; 20, 4: 447-452)
\end{abstract}

Key words: atrial fibrillation, stroke, anticoagulant, epidemiology

\section{Introduction}

While atrial fibrillation (AF) is the most common rhythm disorders observed in our clinical practice, its prevalence in general population is
1-2\% [1]. As an important cause of cardiovascular mortality and morbidity with progressively increasing prevalence, $\mathrm{AF}$ has become a serious health issue recently. In accordance with the increasing and ageing world population, the prevalence of

Address for correspondence: Faruk Ertas, Department of Cardiology, Dicle University Faculty of Medicine, Diyarbakir, Turkey, tel: +90 412 2488001, fax: +90 412 2488523, e-mail: farukertas@hotmail.com 
$\mathrm{AF}$ and $\mathrm{AF}$ related adverse events, especially thromboembolic events, increases. Therefore, current guidelines recommend anticoagulant treatment in patients with moderate to high risk of thromboembolic events [1]. These patients have high scores; a score evaluation system using a 9 point scale (9-point score evaluation) defined as $\mathrm{CHA}_{2} \mathrm{DS}_{2}$-VASc (cardiac failure, hypertension, age $\geq 75$ (doubled), diabetes, stroke (doubled), vascular disease, age 65-74 and sex category [female]) acronym [2]. In our country, the studies conducted on $\mathrm{AF}$, stroke and oral anticoagulant usage are mostly unicenter studies with a limited number of patients and $\mathrm{CHA}_{2} \mathrm{DS}_{2}-\mathrm{VASc}$ score wasn't included [3-5]. Since the multicenter studies have been conducted in western and far eastern populations, they do not reflect the characteristics of the country [6-10].

The aim of this study is to determine the stroke risk of the patients with non-valvular AF, using $\mathrm{CHA}_{2} \mathrm{DS}_{2}$-VASc score based on the records of the multicenter, prospective Atrial Fibrillation in Turkey: Epidemiologic Registry (AFTER) study and to evaluate the profile of anticoagulant medication use in these patients and the accordance with the guidelines.

\section{Methods}

\section{Study design and patient selection}

2242 consecutive patients admitted to the cardiology outpatient clinics of 17 different tertiary health care centers with at least one AF attack determined on electrocardiographic examination. They were included in the study in a manner of reflecting the population of all geographic regions of Turkey [11]. These centers were interviewed and informed about the number of patients that they should admit to the study according to the population of the city. The inclusion criteria were determined as "all consecutive patients over 18 years of age who applied to the cardiology outpatient clinics with at least one attack of AF identified on electrocardiographic examination". Emergency admittances, inpatients, patients who had refused to be included in the study or had not signed the consent form were excluded from the study. Basic demographic data and medical treatments of the patients were assessed. While the patients were being assessed by a cardiologist, the data obtained were being recorded to the patient registry form prepared for the study. Stroke risk was evaluated by $\mathrm{CHA}_{2} \mathrm{DS}_{2}$-VASc score [2]. $\mathrm{CHA}_{2} \mathrm{DS}_{2}$-VASc depends on a point scoring system that gives 2 points stroke and/or transient ischemic attack and 1 point for each of the following factors: age between 65 and 74 years, history of hypertension, diabetes, recent cardiac failure, vascular disease (myocardial infarction, complex atheromatous plaque, prior revascularization, amputation due to peripheral artery disease or peripheral artery disease including angiographic results of peripheral artery disease) and female gender [2]. In terms of stroke risk, the patients were divided into two groups as high risk patients and low risk patients. The patients underwent routine electrocardiographic screening for the assessment of heart failure. Hypertension was described as blood pressure measurement $>140 / 90 \mathrm{~mm} \mathrm{Hg}$, prior diagnosis of hypertension or being on antihypertensive treatment. Diabetes mellitus was described as a fasting blood glucose level of $>126 \mathrm{mg}$, prior diagnosis of diabetes mellitus or being on antidiabetic treatment. A standard registration form was filled for every patient and a consent form was signed by the patients. Ethics Committee consent of the study coordinating center was obtained.

\section{Statistical analysis}

Statistical Package for Social Sciences software (SPSS 12, Chicago, IL, USA) was used for the data analysis. Normality analyses were assessed using Kolmogorov-Smirnow and Shapiro-Wilks methods and data consistent with a normal distribution were given as mean \pm standard deviation and data inconsistent with a normal distribution were given as median (minimum-maximum). In the quantitative comparison of the data, normally disturbed parameters between the two groups were compared using student $t$ test and abnormally disturbed parameters between the two groups were compared using Mann-Whitney U test. Chi-square test was used for the comparison of qualitative data. The independent effect of the variables constituting the $\mathrm{CHA}_{2} \mathrm{DS}_{2}$-VASc acronym on the thromboembolic event was assessed using multivariate analysis. A $p$ value of $<0.05$ was considered significant.

\section{Results}

1745 patients with non-valvular AF were included in the statistical evaluation. Demographic characteristics of the patients included in the study are presented in (Table 1 ). The mean age of the patients was determined as $69.2 \pm 11.5$ years. $78 \%$ of the patients with non-valvular AF had persistent/permanent type of AF. $56 \%$ of the patients with $\mathrm{AF}$ were female. Hypertension was the most common co-morbidity in patients with $\mathrm{AF}(73 \%)$. 
Table 1. Demographic characteristics of the patients.

\begin{tabular}{|c|c|c|c|}
\hline Variable & $\begin{array}{l}\text { Low-intermediate } \\
\text { CHA }_{2} \mathrm{DS}_{2} \text {-VASc score } \\
\text { (n = 227) }\end{array}$ & $\begin{array}{c}\text { High } \\
\mathrm{CHA}_{2} \mathrm{DS}_{2} \text {-VASc score } \\
(\mathrm{n}=1518)\end{array}$ & $\mathbf{P}$ \\
\hline Age [years] & $54.6 \pm 11.1$ & $71.4 \pm 9.8$ & $<0.001$ \\
\hline Female & 55 & 929 & $<0.001$ \\
\hline Body mass index & $27.8 \pm 4.4$ & $28.0 \pm 5.5$ & 0.490 \\
\hline AF type: & & & $<0.001$ \\
\hline First attack & $40(18 \%)$ & $51(3 \%)$ & \\
\hline Paroxysmal & $76(34 \%)$ & $213(14 \%)$ & \\
\hline Persistent & $19(8 \%)$ & $245(16 \%)$ & \\
\hline Permanent & $92(40 \%)$ & $1009(67 \%)$ & \\
\hline Hypertension & $55(24 \%)$ & $1219(80 \%)$ & $<0.001$ \\
\hline Heart failure-LV dysfunction & $15(7 \%)$ & $522(34 \%)$ & $<0.001$ \\
\hline Diabetes mellitus & $6(3 \%)$ & $412(27 \%)$ & $<0.001$ \\
\hline Vascular disease & $12(5 \%)$ & $510(34 \%)$ & $<0.001$ \\
\hline Stroke-TIA-thromboembolism & 0 & $266(18 \%)$ & $<0.001$ \\
\hline History of stroke & 0 & $216(14 \%)$ & $<0.001$ \\
\hline Labile INR & $9(4 \%)$ & $161(11 \%)$ & 0.002 \\
\hline Effective INR ( $n=702$ ) & $31(50 \%)$ & $231(36 \%)$ & 0.031 \\
\hline Ejection fraction & $58.3 \pm 8.7$ & $51.2 \pm 12.8$ & $<0.001$ \\
\hline
\end{tabular}

AF — atrial fibrillation; LV — left ventricular; TIA — transient ischemic attack; INR — international normalized ratio

Among other concomitant risk factors, while the incidences were determined as $31 \%$ for cardiac failure, $30 \%$ for vascular disease and $24 \%$ for diabetes mellitus, smoking was observed in $13 \%$ of the patients. A history of stroke was detected in $15 \%$ of all patients. When the patients were grouped according to the stroke risk based on $\mathrm{CHA}_{2} \mathrm{DS}_{2}-$ -VASc score, $87 \%$ of the patients were determined to have high risk, $9 \%$ intermediate risk and $4 \%$ low risk. When the patients of low and intermediate risk groups were compared with the patients of high risk group, statistically significant differences were observed in all demographic characteristics with the exception of body mass index. As expected, in the high risk group, the rates of the variables constituting $\mathrm{CHA}_{2} \mathrm{DS}_{2}$-VASc acronym were higher. However, the rate of labile international normalized ratio (INR) was higher and the mean ejection fraction (EF) was lower (Table 1). As the $\mathrm{CHA}_{2} \mathrm{DS}_{2}$-VASc score increased, the rate of stroke increased (Fig. 1).

The only independent risk found was age, in the multivariate analysis assessing the independent effects of the variables constituting the $\mathrm{CHA}_{2} \mathrm{DS}_{2}$-VASc acronym, on the thromboembolic event ( $\mathrm{OR}=1.026$; 95\% CI 1.013-1.039; $\mathrm{p}<0.001$ ) (Table 2).

When the patients were assessed in terms of anticoagulant/antiplatelet medication profile, $25 \%$ of the patients were on warfarin treatment alone, 15\% of the patients were on warfarin + acetylsalicylic acid (ASA) treatment, $42 \%$ were on ASA treatment alone and $18 \%$ of the patients were not using any of these treatment options. The use of oral anticoagulant/antiplatelet medications according to the stroke risk groups are shown in Figure 2. Accordingly, though it was not necessary, $23 \%$ of the individuals with low risk were using warfarin. However, $58 \%$ of the patients were not on anticoagulant treatment.

When the whole cohort is considered, whilethe patients on oral anticoagulant treatment constituted $40 \%$ of all patients, effective INR level (2.0-3.0) was achieved only in $37 \%$ of these patients. When the patients with high risk, according the $\mathrm{CHA}_{2} \mathrm{DS}_{2-}$ -VASc score, were assessed, the most common cause of not receiving anticoagulation therapy was the medication not being prescribed by the physician $(70 \%)$. This was followed by socioeconomic reasons with a percentage of $16 \%$ and medical contraindications with a percentage of $7 \%$. Reasons related to the patients were refusal of treatment with a percentage of $4 \%$ and discontinuation of the treatment with a percentage of $3 \%$.

\section{Discussion}

The present study is a multicenter, prospectively designed study of non-valvular AF. According 


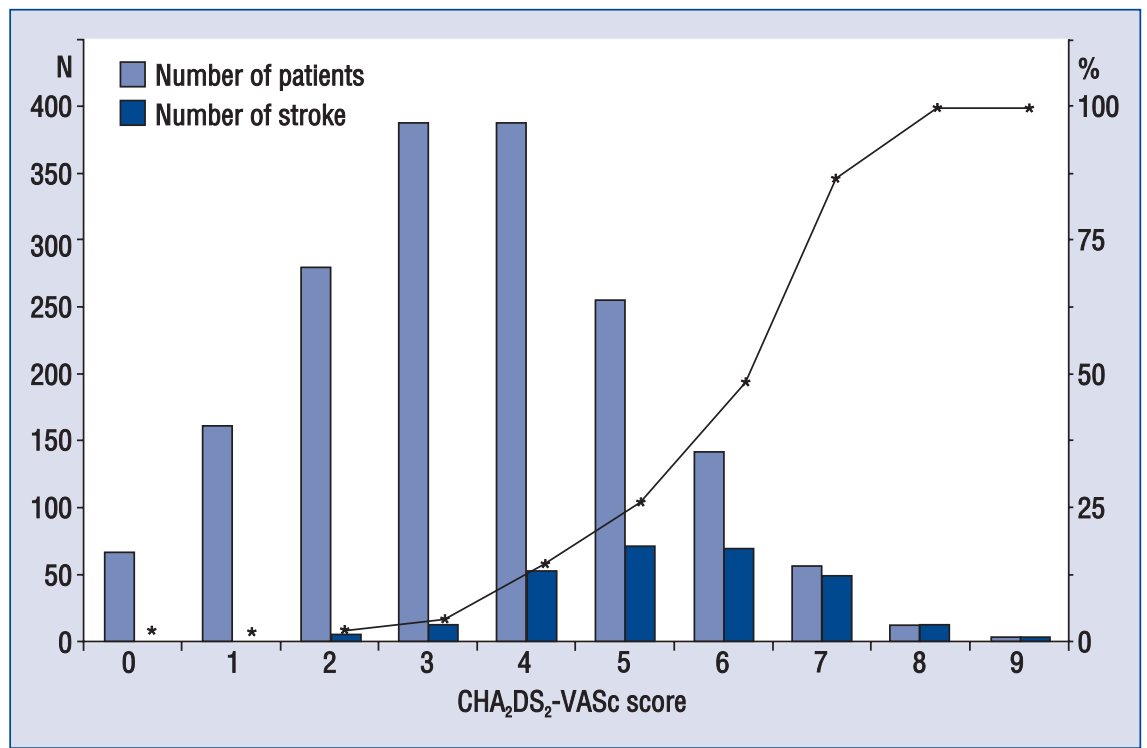

Figure 1. The relationship between $\mathrm{CHA}_{2} \mathrm{DS}_{2}$-VASc scores and number of patients with stroke; * percentage of stroke.

Table 2. Logistic regression analysis of the independent predictors of stroke/transient ischemic attack/ thromboembolic events.

\begin{tabular}{lccc}
\hline Variable & Odds ratio & 95\% confidence interval & P \\
\hline Age & 1.026 & $1.013-1.039$ & $<.001$ \\
Sex & 1.105 & $0.839-1.455$ & 0.479 \\
Hypertension & 1.257 & $0.909-1.737$ & 0.166 \\
Heart failure & 0.955 & $0.704-1.296$ & 0.768 \\
Vascular disease & 1.205 & $0.893-1.625$ & 0.222 \\
Diabetes mellitus & 1.111 & $0.816-1.513$ & 0.504 \\
\hline
\end{tabular}

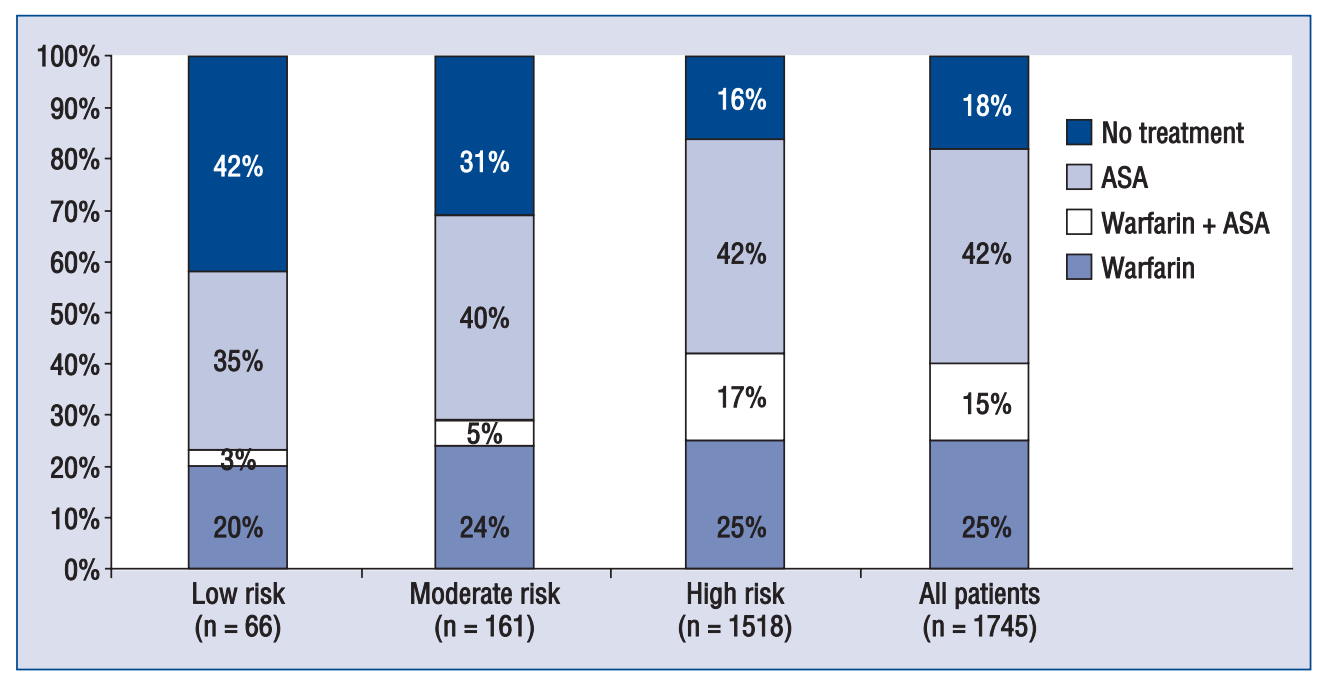

Figure 2. The use of oral anticoagulant/antiplatelet medications according to the stroke risk groups; ASA — acetylsalicylic acid. 
to the analysis of the preliminary data, $4 / 5$ of $\mathrm{AF}$ cases were included in the persistent/permanent group. The frequency in females was higher than in males. The most common concomitant risk factor was hypertension. According to $\mathrm{CHA}_{2} \mathrm{DS}_{2}{ }^{-}$ -VASc score, while $87 \%$ of the patients were high risk patients, only $42 \%$ of these patients were on oral anticoagulant treatment. The major reason for not receiving oral anticoagulant in spite of medical indication was determined as physician's neglect.

One of the results of the AFTER study that differ from that of the literature was the determination of an incidence in females surpassing the incidence in males with a percentage of $22 \%$. However, the incidence of AF was 1.5 to 2 times higher in females than in males according to the records of Framingham studying American Society and Euro Heart Survey studying European societies [12,13]. Although our results appear to contradict these data, they support the data of TEKHARF study (Cardiac Diseases and Risk Factors in Adults in Turkey), the epidemiological study on AF in Turkey [14]. When assessed according the geographical regions of Turkey, no difference was detected between female/male distribution. This observation suggests that the aforementioned result is a demographic characteristic specific to our society. In a study of 1084 patients with non- valvular AF conducted by Lip et al. [2] — the one who introduced the $\mathrm{CHA}_{2} \mathrm{DS}_{2}-\mathrm{VASc}$ risk score to the literature - the most common comorbidity in $\mathrm{AF}$ was demonstrated as hypertension. In our study, while hypertension was observed in a similar rate, vascular disease was observed in a lower frequency and heart failure, history of stroke and diabetes mellitus were observed at a higher frequency.

Euro Heart Survey Investigators showed that, when assessing the independent effect of all potential risk factors on thromboembolic events, female gender was the only significant associated factor $(\mathrm{OR}=2.53$; 95\% CI 1.08-5.92; $<<0.29)$. However, in our cohort, the multivariate analysis revealed age as the only significant factor.

In the Euro Heart Survey study [15] of 2706 patients with $\mathrm{AF}$, when the patients were assessed in terms of oral anticoagulant/antiplatelet medication profile, $57 \%$ of all patients were on warfarin treatment alone, $7 \%$ were on warfarin + ASA treatment, $27 \%$ were on ASA treatment alone, and $9 \%$ of the patients were not using any of these treatment options. In our study, while the rate of oral anticoagulant use was $40 \%$, ASA use was approximately 2 times higher. In the J-RYHTHM
[6] study which was conducted in Japan, while the rate of anticoagulant use was $87 \%$, the rate of ASA use was found to be $22 \%$. In the subgroup analysis [16] of the same study, $89 \%$ of the 6324 patients with non-valvular $\mathrm{AF}$ were on warfarin treatment and $23 \%$ were on ASA treatment. In this study too, only in $34 \%$ of the patients the effective INR level (2.0-3.0) was achieved. When the data of our study were compared with these results, while the rates of warfarin use were dramatically lower, the effective INR levels were achieved at a rate surprisingly similar to the rate of the aforementioned study. When considering that the most common cause of not receiving anticoagulant medication was that in $70 \%$ of cases the medication was not prescribed by the physician, one may suppose that our physicians attach a particular importance to warfarin monitoring and surpassing the value reported in the literature. However, the detection of the rate of unnecessary use of warfarin as $23 \%$ in the low risk group reveals that the guidelines are not followed in the anticoagulation management. In this way it emphasizes the important barrier concerning warfarin. Therefore, novel anticoagulants will be welcomed in real world practice against stroke prevention in patients with AF [17-20].

\section{Conclusions}

According to the results of our study, the stroke prevalence in patients with non-valvular $\mathrm{AF}$ was $15 \%$ and all of these patients were included in high risk group according to the $\mathrm{CHA}_{2} \mathrm{DS}_{2}$-VASc score. Age was the most powerful independent determinant of stroke. The major cause of the anticoagulation rate of $40 \%$ and the prevalence of $37 \%$ in achieving the effective INR levels and not receiving anticoagulant medication was the physician's neglect. These results suggest that in our clinical practice of non-valvular AF, particularly in the treatment field, one shall pay more attention to the stroke risk scores indicated by guidelines and anticoagulation shall be managed according to these guidelines.

\section{Conflict of interest: none declared}

\section{References}

1. European Heart Rhythm Association; European Association for Cardio-Thoracic Surgery, Camm AJ, Kirchhof P, Lip GY et al. Guidelines for the management of atrial fibrillation: The Task Force for the Management of Atrial Fibrillation of the European Society of Cardiology (ESC). Eur Heart J, 2010; 31: 2369-2429. 
2. Lip GY, Nieuwlaat R, Pisters R, Lane DA, Crijns HJ. Refining clinical risk stratification for predicting stroke and thromboembolism in atrial fibrillation using a novel risk factor-based approach: The Euro Heart Survey on Atrial Fibrillation. Chest, 2010; 137: 263-272.

3. Ertaş F, Duygu H, Acet H, Eren NK, Nazli C, Ergene AO. Oral anticoagulant use in patients with atrial fibrillation. Turk Kardiyol Dern Ars, 2009; 37: 161-167.

4. Ertaş F, Kaya H, Atılgan ZA et al. Predictors of warfarin use in patients with non-valvular atrial fibrillation who presented to the cardiology outpatient clinic of a tertiary hospital in Turkey: An observational study. Turk J Med Sci, 2012; 42: 1172-1179.

5. Karaçağlar E, Atar I, Yetiş B et al. The frequency of embolic risk factors and adequacy of anti-embolic treatment in patients with atrial fibrillation: A single tertiary center experience. Anadolu Kardiyol Derg, 2012; 12: 384-390.

6. Atarashi $\mathrm{H}$, Inoue $\mathrm{H}$, Okumura $\mathrm{K}$, Yamashita $\mathrm{T}$, Kumagai N, Origasa H; J-RHYTHM Registry Investigators. Present status of anticoagulation treatment in Japanese patients with atrial fibrillation: A report from the J-RHYTHM Registry. Circ J, 2011; 75: 1328-1333.

7. Waldo AL, Becker RC, Tapson VF, Colgan KJ; NABOR Steering Committee. Hospitalized patients with atrial fibrillation and a high risk of stroke are not being provided with adequate anticoagulation. J Am Coll Cardiol, 2005; 46: 1729-1736.

8. Nabauer M, Gerth A, Limbourg T et al. The Registry of the German Competence NETwork on Atrial Fibrillation: Patient characteristics and initial management. Europace, 2009; 11: 423-434.

9. Bilato C, Corti MC, Baggio G et al. Prevalence, functional impact, and mortality of atrial fibrillation in an older Italian population (from the Pro.V.A. study). Am J Cardiol, 2009; 104: 1092-1097.

10. Shin HW, Kim YN, Bae HJ et al. KORAF Investigator. Trends in oral anticoagulation therapy among Korean patients with atrial fibrillation: The KORean Atrial Fibrillation Investigation. Korean Circ J, 2012; 42: 113-117.
11. Ertaş F, Kaya H, Yüksel M, Soydinç MS, Alan S, Ulgen MS. Atrial Fibrillation in Turkey: Epidemiologic Registry (AFTER) study design. Anadolu Kardiyol Derg, 2013; doi: 10.5152/akd.2013.073 [Epub ahead of print].

12. Lloyd-Jones DM, Wang TJ, Leip EP et al. Lifetime risk for development of atrial fibrillation: the Framingham Heart Study. Circulation, 2004; 110: 1042-1046.

13. Nieuwlaat R, Capucci A, Camm AJ et al. Atrial fibrillation management: a prospective survey in ESC member countries: The Euro Heart Survey on Atrial Fibrillation. Eur Heart J, 2005; 26: 2422-2434.

14. Uyarel H, Onat A, Yüksel H, Can G, Ordu S, Dursunoğlu D. Incidence, prevalence, and mortality estimates for chronic atrial fibrillation in Turkish adults. Turk Kardiyol Dern Ars, 2008; 36: 214-222.

15. Nieuwlaat R, Capucci A, Lip GY et al. Euro Heart Survey Investigators. Antithrombotic treatment in real-life atrial fibrillation patients: A report from the Euro Heart Survey on Atrial Fibrillation. Eur Heart J, 2006; 27: 3018-3026.

16. J-RHYTHM Registry Investigators. Determinants of warfarin use and international normalized ratio levels in atrial fibrillation patients in Japan. Subanalysis of the J-RHYTHM Registry. Circ J, 2011; 75: 2357-2362.

17. Connolly SJ, Ezekowitz MD, Yusuf S et al. RE-LY Steering Committee and Investigators. Dabigatran versus warfarin in patients with atrial fibrillation. N Engl J Med, 2009; 361: 1139-1151.

18. Paikin JS, Manolakos JJ, Eikelboom JW. Rivaroxaban for stroke prevention in atrial fibrillation: a critical review of the ROCKET AF trial. Expert Rev Cardiovasc Ther, 2012; 10: 965-972.

19. Lopes RD, Al-Khatib SM, Wallentin L et al. Efficacy and safety of apixaban compared with warfarin according to patient risk of stroke and of bleeding in atrial fibrillation: A secondary analysis of a randomised controlled trial. Lancet, 2012; 380: 1749-1758.

20. Miller CS, Grandi SM, Shimony A, Filion KB, Eisenberg MJ. Meta-analysis of efficacy and safety of new oral anticoagulants (dabigatran, rivaroxaban, apixaban) versus warfarin in patients with atrial fibrillation. Am J Cardiol, 2012; 110: 453-460. 